\title{
Attracting and Retaining Competitive Faculty - Startups, Core Facilities, and Investment Strategies...Oh My!
}

\author{
Peter K. Dorhout, Vice President for Research \\ Kansas State University
}

$\mathbf{T}$

his paper explores the challenges of attracting and retaining competitive faculty at Kansas State University. In order to reach its strategic goal to be a top 50 public research university by 2025 , the university has focused on student achievement, retention, and success, along with responding to state initiatives to provide more engineering graduates to meet future state needs. Kansas State is committed to supporting its faculty and graduate programs by developing strategies to improve salaries and other forms of support. A key factor in meeting the goal of a top 50 university, is the ability to grow the research enterprise through focused investments in core facilities and institutional support structures that will enable faculty to be competitive for extramural funding, particularly in interdisciplinary and inter-institutional grant programs. Moreover, improving the policies and processes that enable partnerships with industry to flourish and faculty to pursue patents and technology licenses will open new doors for the institution. In an environment of diminishing state appropriations for higher education, it has become more critical to develop diversified strategies to fund startup commitments for faculty and core facilities that will support new hires or retain key members of our community.

The presentation that follows builds off of the anxiety that I experienced starting my position as the Vice President for Research in 2016. Startups, core facilities, and investments...oh my. This anxious chant, which has hounded my first six months on the job, reminded me of a famous journey for a young girl in Kansas, set in earlier days, and the challenges facing Metro-Goldwyn-Mayer studios in the 1930s to adapt a children's story to new film-making technologies and a broader audience of movie fanatics. Does the metaphor of creating a movie during the Depression, investing in new technologies and methods, and taking chances on new actors and actresses compare with my challenges and opportunities? Does the storyline of Dorothy's journey align with the broader university research enterprise? Startups, core facilities, and investments...oh my...three very scary creatures in the university jungle.

The Opening - Scene 1. The Talk.

The invitation to speak at the Merrill Research Retreat in July 2016, came with the caveat that I could speak about anything I desired, but the organizers needed the title as soon as possible. What had been plaguing my thoughts as a new vice president for research at Kansas State University were the requests that seemed to be rolling in near the end of the fiscal year for budget reduction plans. Kansas 
was enjoying another in a long litany of missed monthly revenue targets for the state, which was putting pressure on the annual appropriation for higher education.

Kansas State University was also completing the first five years of an ambitious fifteen-year strategic plan to become a top 50 public research university by 2025 , during which time state revenues were not supporting the necessary investments for sustainable growth in the research enterprise. We were entering the perfect storm of flattening student enrollments (high school enrollments were declining), increasing retirements (aging baby boomers), and a reduced state appropriation (state revenues). Finding resources to address faculty retention and hiring quickly rose to the top of my concerns list.

Startups, core facilities, and investment strategies for research are the keys to attracting and retaining competitive faculty. Startups, core facilities, and investments...oh my.

The 2014 Higher Education Research and Development survey ${ }^{1}$ may be interpreted to reveal the rank ordering of public universities in the U. S., where it placed Kansas State in the $73^{\text {rd }}$ spot on the list. The Arizona State University Center for Measuring University Performance placed K-State at number 70 in its 2014 annual report on Top American Research Universities. ${ }^{2}$ To be included in the top 50 public university ranks, Kansas State will need to increase its annual research expenditures by nearly a factor of 1.75 by 2025.

Such a goal is neither inconceivable nor impossible. Compounded growth at
$6.5 \%$ per year will exceed our goal. From 1990 to 2000, the research expenditures at Kansas State grew by $9.5 \%$ per year. ${ }^{3}$ During that same period, the increase in federal research spending was nearly flat, growing only by $3 \%$ over the entire tenyear period. ${ }^{4}$ From 2000 to 2010, the research expenditures at Kansas State grew by $7.5 \%$ per year; the federal budget for research grew by $4 \%$ per year. Even as the federal research expenditures contracted from 2010 to 2015 by $4 \%$ per year, the research expenditures at Kansas State grew by $3.8 \%$ per year.

Since 1990, the university has consistently out-performed the federal research budget growth or contraction, but have we reached that fork in the road where the wrong choice may take us off the smooth path? Will our confluence of budgetary low-pressure systems bring about a perfect wall cloud to whip up a fury of tornadic winds that will bring down our house? Startups, core facilities, and investments...oh my. This sounds familiar....

\section{Flashback - Scene 2.}

I imagine the Metro-Goldwyn-Mayer writers in mid 1936, 80 years prior to this research retreat of the Merrill Research Center, struggled with their perfect storm following some lean years. MGM, only recently converted to "talkies" and starting to compete well for talent and a share of the movie industry, was seeking a block buster movie following the death of Irving Thalberg. ${ }^{5}$ United Artists group, including Walt Disney and Hal Roach, was competing successfully for market share, and the new technologies of the time - sound, color movies, and other cin- 
ematic shifts - were impacting the business. ${ }^{6}$ Nevertheless, the Depression had taken its toll on the movie industry, which, by 1936, was beginning to enjoy a renaissance due to new technologies and equipment. ${ }^{7}$

In 1938, writers began working with the script for a fantasy story that had flopped as a movie in the mid 1920s, but had renewed interest given the color technology of the time. ${ }^{8}$ Disney had penned a contract for exclusive rights for the Technicolor three-strip process for cartoons in 1934, with an embargo until 1936, and he was in the production phase of Snow White, which was released in 1937. MGM was looking for a hit, but it would come at a cost. The startup was incredible - the mechanics of Technicolor filming and showing in the mid-1930s was cumbersome and incredibly costly, recruiting and retaining new actors and actresses to play the parts were challenging, and the investments would not pay off for almost 10 years.

So, when production began in 1938 on The Wizard of $\mathrm{Oz}$, the storm had not yet cleared. MGM was also betting on another major book to become a blockbuster motion picture: Gone with the Wind started production the same year, and it would steal away one of the $\mathrm{Oz}$ directors. Buddy Ebson, first cast as the Tin Man, suffered a reaction to the aluminum paint used on him and had to leave the filming. ${ }^{9}$ The cast of munchkins and Emerald citizens commanded a colossal costume budget. The film's special effects left a number of critics wanting for something better, and while nominated for an Academy Award, the Best Picture Award went to Gone with the Wind. Best Song and Best
Original Score awards were the only two accolades received for the film in 1940. It would be nearly 70 years later that the American Film Institute listed The Wizard of $\mathrm{Oz}$ among the Top 100 movies, songs, and quotes, including one that is dear to us in Kansas, "Toto, I've got a feeling we're not in Kansas anymore."

Present Day - Scene 3. The Leader.

Compare and contrast the university version of the challenges of attracting, retaining, and investing in the faculty and the research enterprise with those experienced by Director Victor Fleming, who also left $\mathrm{Oz}$ to finish Gone with the Wind. So, let's focus first on the change in leadership. The screenplay for $\mathrm{Oz}$ did undergo regular tweaking as scenes were rehearsed, filmed, and reviewed. Like a university Strategic Plan, the screenplay lays out a basic vision and framework for the movie, but reality sometimes gets in the way. As the directors changed, some of the character traits changed, altering slightly or significantly from the way L. Frank Baum envisioned them. Indeed, this is a delicate balance between how so many readers of the $\mathrm{Oz}$ series of books viewed the characters and their personalities and how they should appear on film - the difference between fame and flop often lies in the balance.

University leaders are faced with the inherited legacies of those who led before them: Strategic Plans, alumni culture, and campus culture - "we've always done it this way." When leadership changes, there is a moment of chaos when people question the script, the blocking, and the character relationships. Will the Strategic Plan still be valid with the new leader? Will we continue to follow our 
previous processes for making decisions? Will the institutional supporters continue to help meet the financial goals of the Plan?

Unlike the screenplay, the university community should be involved in creating the Strategic Plan. The leader provided some of the vision, but the "cast" is engaged in creating the living document that moves the story forward. While the paths to get to the desired outcome may be different under new leadership, or as a result of changing funding climates, the goal or goals should remain the same.

An effective Plan should be developed from the ground up, not the top down, so the "screenplay" should be owned by the entire cast, which is what makes it the strongest document it can be. ${ }^{10}$ Yet, the university should not be considered only as an "organization as theater," which serves as the metaphor for this paper. Bolman and Deal wrote, "the symbolic frame encourages us to view organizations as theater and organizational activities as dramaturgical performances played to both internal and external audiences," when considering strategic planning. ${ }^{11}$ Citing Cohen and March, "there are four symbolic roles for plans in universities: 1 . Plans are symbols; 2 . plans become games; 3 . plans become excuses for interactions; and 4 . plans become advertisements." 12

Flashback - Scene 4. The Plan.

There are four symbolic roles for the Plan. First, there is the symbol itself. The Plan could symbolize that "all's well, and even better just around the corner." For Dorothy and her traveling companions in the story, the symbol is the Emerald City - that's where the Wizard resides, and, to paraphrase Kander \& Ebb, ${ }^{13}$ if they could make it there, they could make it anywhere. I appreciate that I should not mix the story line of $\mathrm{Oz}$ with the making of the movie, but the two are intertwined. The dynamic environment of the movie production was influenced by the characters and morals of the story as well as by the dynamics of the leadership and the technology changes impacting filming. The screenplay, and arguably the story within it, were part of the symbolic Plan.

When Plans become games, they embark on a new line of strategy - a test of wills. Within the story of $\mathrm{Oz}$, Dorothy and the Witch were engaged in a test of wills, as were her three traveling companions who were trying to storm the castle to save her. Within the filming and production of the movie, there was a test of wills between actors, directors, and producers, each with his or her own vision of how the story should be portrayed.

Screenplays do become susceptible to changing conditions. So, too, with Strategic Plans. For example, not reaching a particular goal or metric is often a time to retrench and refresh the Plan. Not having the technology yet to float a Good Witch in a bubble or melt a Not-So-Nice Witch, meant changing the scenes rather than bringing the cast together to discuss how to move forward with the available technologies. When we in the university setting have a Plan, it is often the excuse for not discussing tactics any longer, which often creates animosity towards the Plan and not the leaders who are using it in this manner.

Finally, ever mindful of the patrons of the project, the screenplay can often be 
used as an advertisement for the beauty of the finished product. $\mathrm{Oz}$ showcased fantasy in a manner not yet seen by audiences of the times. The Emerald City idolized the good life of the average Emeraldcitizen, complete with the full makeover of the day. The movie itself became an advertisement for new color cinematography and a rising singing star under contract with MGM.

The Strategic Plan for transforming any organization, like the screenplay for $\mathrm{Oz}$, is only as good as the talent it guides and the leadership that embraces creativity and finds a path forward. A screenplay does not mention all of the blocking and tackling required on each scene, let alone outline precisely what success will resemble when completed, and a Plan does not necessarily provide all of the tactics required to be successful. Implementation will be fraught with obstacles easily be enhanced by the talent that it gathers along the way.

Present Day - Scene 5. Change for the Better.

Investment strategies are unique to each institution and situation, but they reach back to the screenplay, and the ultimate goal. For Kansas State, that goal is to become a Top 50 Public Research Institution by 2025 . No strategies or tactics there. No metrics other than how the nation defines top 50 universities. In the opening scene, I set the stage for how that goal would be measured and cited research and development spending. The government spending trend on R\&D actually pales in comparison to the overall

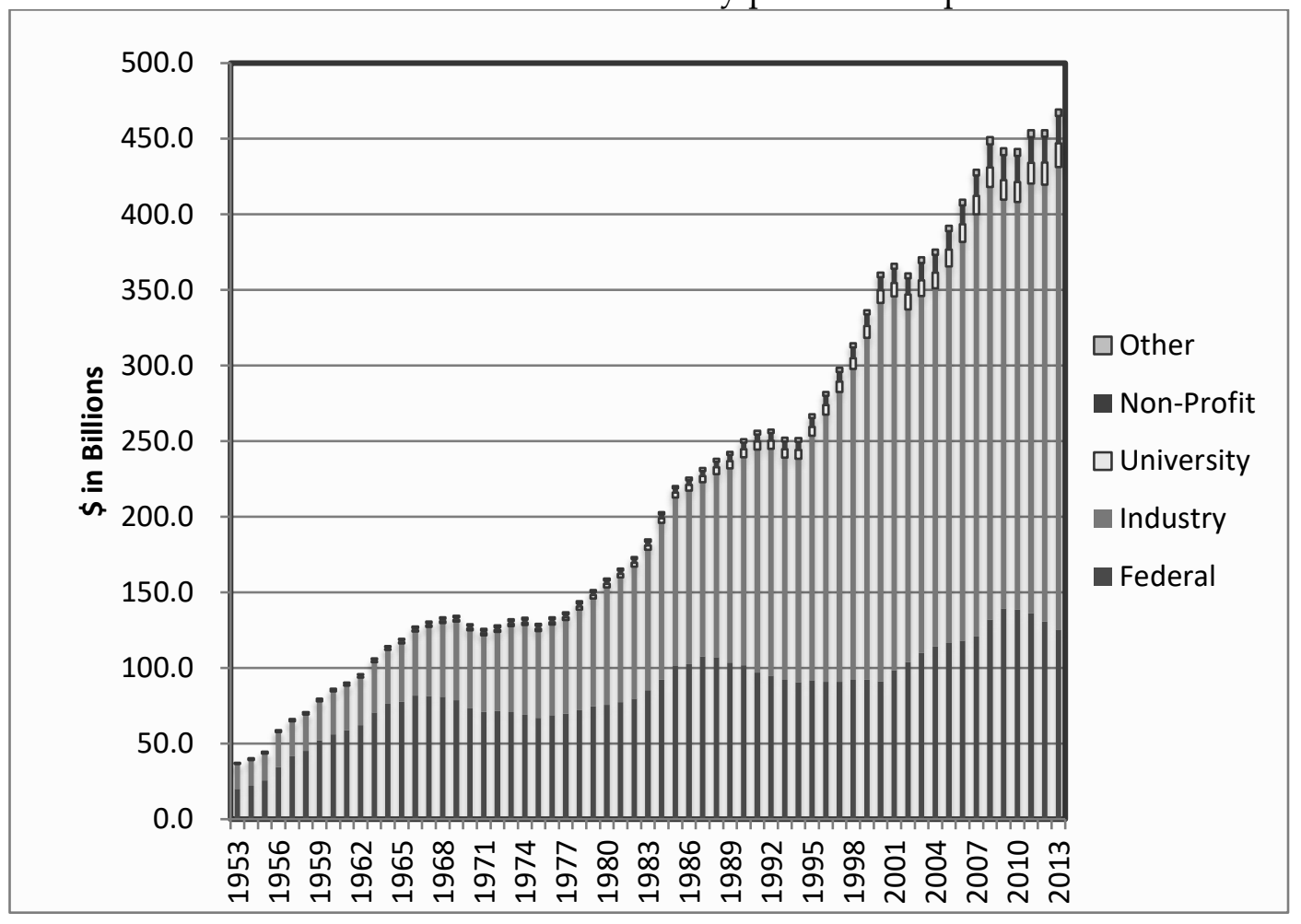

Figure 1. Total Research \& Development Spending by Sector Over 60 Years 
spending by industry and others. ${ }^{4}$ Consider the graph in Figure 1 constructed from data from AAAS. In 1990, the federal government provided $40 \%$ of the total investment in R\&D funding in the U. S. By 2010, that fraction fell to $30 \%$ of a total expenditure profile that increased by $77 \%$, from roughly $\$ 250$ billion per year to over $\$ 443$ billion per year. Industry investments in research during this 20 -year period grew by nearly $100 \%$ compared to the growth in federal investments of only 36\%. Moreover, 2010 represented a high-water mark for federal R\&D spending.

Not all R\&D funding is created equal. The share of federal R\&D funding going to academic basic research has been steadily growing from the 1950s until today, ${ }^{14}$ with roughly $24 \%$ of the total $R \& D$ funding directed to basic research, of which over half goes to universities. Another $24 \%$ of the federal R\&D budget is directed to applied research, of which about $25 \%$ goes to university research efforts. The largest share of federal funding, over $50 \%$, goes to support development, and universities are very small players in this area. In fact, in the larger picture of a $\$ 450$ billion per year total R\&D budget in the U.S., only about $15 \%$ funded university research, basic, applied, and development, in 2013. The portfolio of research at Kansas State University in 2014 was not much more diversified than many other public research universities. ${ }^{1}$ Only 3\% of the total research expenditures for K-State came from industry partners in research. About the same percentages each came from each private foundations and gifts.
Support for our research enterprise originated from federal grants (roughly 33\%), institutional funds (33\%), and the balance from state and local funding (25\%). Based on the sector where the funding is or is not poised for growth, the research enterprise at K-State could be greatly enhanced by creating a culture that embraces industry partnerships; moreover, such a culture aligns with our land-grant mission, which is dedicated to bringing our new knowledge out to the public for public consumption.

Investing in research to grow the enterprise includes supporting infrastructure, facilities, and new faculty hiring strategies. Facilities and Administrative costs charged to grants should be dedicated to investments in the research infrastructure. However, changing state budgets have meant that some of those resources have been redirected to cover budget shortfalls in research support areas. Building and deferred maintenance budgets have also been impacted that also stress the F\&A resources. Startup costs for new faculty hiring have been growing each year. The annual report from Burroughs-Wellcome in 2010 put average startup costs over $\$ 800,000$ for biomedical sciences faculty, over $\$ 710,000$ for physical sciences, and $\$ 720,000$ for engineering faculty, and it hasn't gotten cheaper. ${ }^{15}$

With diminishing state resources putting pressure on $\mathrm{F} \& \mathrm{~A}$ budgets, investing in core facilities or other areas of the research enterprise has become challenging. Faculty salary stagnation due to state budgetary pressures has put many of our best performers at risk for being recruited away. Recruiting and retaining 
faculty has become a perennial challenge for state universities, particularly given the resource constraints. Nevertheless, we must be strategic in our hiring as outstanding faculty retire and as programs grow to meet student demands.

Universities must identify their strengths and invest in core facilities that permit groups of faculty and staff to work collaboratively around larger projects. While shared equipment may not be ideal in some cases, larger equipment that requires a support infrastructure to maintain it or staffing to train students to use it will be less cost-prohibitive. While operating as pure cost centers is not often sustainable, some central support for shared facilities can reduce the costs to research grants and contracts. For some institutions, this model is a culture shift from how things have been.

While these changes may not seem like they are for the better, changes such as these can be for good. The sustainability of public and land-grant research universities depends on culture change. Partnering with industry, large or small, ensures that our research is supported through diversified funding sources and that our best ideas are making it to the market place. Evaluating investment strategies for our limited Facilities \& Administrative resources should ensure sustainability of our strengths and enable us to continue to educate the students who become our next generation of Kansas professionals.

Present Day - Scene 6. There's No Place Like Home.

After more than a decade in theaters, during a very difficult time in our nation's history, $\mathrm{Oz}$ finally turned a profit and became one of our most beloved films. Good had triumphed over evil on so many fronts. In the 1940s, millions of young Americans made journeys that they never should have made, and many made the ultimate sacrifice so that good would prevail. Dorothy's journey would serve as a metaphor for so many different coming-of-age events; the story is timeless and easily understood by generations since and to come.

Does the journey of the making of $\mathrm{Oz}$ serve as a good metaphor for the comingof-age for the research enterprise? I submit that it does. Ihave accounted for prohibitive costume and special effects costs, technology costs in filming, and the competition with other films luring away some of the best actors and directors of the times. I accounted for changing plans that impacted what the viewers saw on film and how the characters were portrayed. Plans and screenplays that, when proven to be inflexible and unresponsive to changing conditions, find their way into the dustbin of history. So, too, will be the fate of our plans for transforming the research enterprise if we ignore the opportunities to adjust our strategies as the conditions warrant.

“But wait," you say? "Haven't you forgotten the ending of the story?"

On the remote chance that you, the reader, grew up in an environment devoid of this particular movie or book, I will not provide a spoiler. I will tell you that Dorothy matured during her time in $\mathrm{Oz}$ and mustered the wisdom, the courage, and the heart to succeed on her personal journey. She was confronted by the allure of the newness and the color of a magical place, yet she prevailed. To use 
the university as a metaphor for her experience, she had an unusual internship opportunity, she networked with the denizens of $\mathrm{Oz}$, and she was able to work with a diverse team of interdisciplinary colleagues. Sometimes the critical infrastructure to support her journey was paved with gold, and other times it was a foreboding and entangling forest of selfdoubt and fear. The Wizard who was "all powerful" and came across gruff, turned out to be a horse of a different color. In short, Dorothy grew up.

Why do we gather each year with colleagues, mustered together by the leadership of the Merrill Advanced Studies Center at the University of Kansas, to fo-

\section{References}

${ }^{1}$ https://www.nsf.gov/statistics/srvyherd/

${ }^{2}$ https://mup.asu.edu/Top-Universities

${ }^{3}$ http://www.k-state.edu/research/ourresearch/facts-figures.html

${ }^{4}$ https://www.aaas.org/page/historicaltrends-federal-rd

${ }^{5}$ International Directory of Company Histories, Vol. 25. St. James Press, 1999.

6 T. Elway, Popular Science, 1923, 59.

${ }^{7}$ H. Kalmus, J. Soc. Motion Picture Eng., 1938, 52.

8J. Frick et al., The Wizard of Oz: The Official 50th Anniversary Pictorial History. 1986, New York, NY: Warner Books, Inc. ${ }^{9} \mathrm{~A}$. Smalling, The Making of the Wizard of Oz: Movie Magic and Studio Power in the Prime of MGM. 1989, New York, NY, Hyperion. cus on improving the research environment for our institutions? I do not believe that the conference is organized to share only what we have done, or done well, but what we are going to do, the journey we will take, and the revelations we will bring back. Why we gather together across the four-state region to confront our challenges and combat our demons is not to boast about our talents, but to address our issues through collective dialog and interaction. Our journey at Kanas State is one that is focused on improving our part of the world, changing for the better so our students and faculty will prevail, because there really is no place like home.

${ }^{10} \mathrm{~J}$. H. Zenger, J. Folkman, "The Extraordinary Leader," 2002, New York, NY, McGraw-Hill.

${ }^{11}$ L. G. Bolman \& T. E. Deal, "Reframing Organizations, $3^{\text {rd }}$ Ed.," 2003, New York, NY, Wiley \& Sons.

${ }^{12}$ M. Cohen \& J. G. March, "Leadership and Ambiguity," 1974, New York, NY, McGraw-Hill. ${ }^{1}$ J. Kander \& F. Ebb, "New York, New York," 1977, Copyright, United Artists Co..

${ }^{13}$ https://ncsesdata.nsf.gov/fedfunds/2014/

${ }^{14}$ Burroughs-Wellcome 2010 Fund Report, www.bwfund.org last accessed July, 2016.

${ }^{15}$ Burroughs-Wellcome 2010 Fund Report, www.bwfund.org last accessed July, 2016. 